\title{
Evidence of a foetal role in determining the length of gestation
}

\author{
A. C. Turnbull \\ M.D., F.R.C.O.G. \\ AnNe B. M. Anderson \\ M.D. \\ Department of Obstetrics and Gynaecology, Welsh National School of Medicine, Cardiff
}

THIs paper reviews evidence that the foetus plays a vital role in determining gestation at labour. The hypothesis was not the keystone of our work initially, but evidence of foetal regulation of the myometrium became increasingly apparent during the course of studies on uterine contractility in human pregnancy.

Work on induction of labour (Turnbull \& Anderson, 1967, 1968a, b) made us aware of the great variation from patient to patient in the level of spontaneous uterine activity in late pregnancy. We also observed that uterine sensitivity to oxytocin was greater in cases delivered at term than in those with prolonged pregnancy. However, we did not know from this whether uterine sensitivity to oxytocin, probably in conjunction with spontaneous activity, declined with advancing gestation beyond term, or whether the uterus had been insensitive and inactive throughout pregnancy.

Factors relating to length of gestation in human pregnancy

\section{Uterine contractility}

Further investigation showed that the length of human pregnancy was determined by the level of uterine contractility present for many weeks before the onset of labour. The uterus was quiescent up to the 20th week, when some co-ordinated activity started in all patients (Anderson \& Turnbull, 1968). Activity was greater in some patients however; in these there was a further increase in uterine activity between 32 and 36 weeks and labour always started before term, although not usually before 38 weeks. In the others, there was relatively little uterine contractility throughout pregnancy and the onset of labour was delayed past term (Turnbull \& Anderson, 1968c). The patients in these studies were healthy young primigravidae in whom there was no doubt about the menstrual data or duration of pregnancy.

\section{Cervical dilatation}

In a larger series of primigravidae, selected with the same criteria of normality, we found that changes in the cervix during pregnancy paralleled uterine activity. For example, at the 32 nd week of pregnancy, the internal os was 1-2 cm dilated in all patients who subsequently delivered by the 38th week but in only $10 \%$ of those whose pregnancy continued to the 42 nd week or later. These changes in the cervix could be detected as early as the 24 th week.

Thus, in human pregnancy, the factors which control the time in gestation when labour starts may be operative for many weeks beforehand.

\section{Urinary oestrogens}

The evidence for a foetal role in regulating human uterine contractility was provided by measuring the urinary excretion of oestriol and oestrone at the 34th and 37th weeks of pregnancy. In patients with a high level of uterine activity and an early onset of labour, oestriol excretion was high and oestrone low. The lower the urinary oestriol or the higher the oestrone at that stage, the more prolonged was the pregnancy. Pregnanediol excretion was not related to gestation at labour (Turnbull, Anderson \& Wilson, 1967). Klopper \& Billewicz (1963) showed that, the higher the maternal urinary excretion of oestriol at the 38th week of gestation, the nearer was delivery.

It is well known that the foetus plays an active role in oestrogen metabolism (Diczfalusy et al., 1961) and at least $70 \%$ of oestriol excreted in the maternal urine is of foetal origin (Cassmer, 1959; Klopper, Turnbull \& Anderson, 1966). The high oestriol or low oestrone levels associated with impending labour may represent a high conversion of oestrone to oestriol within the foeto-placental unit, or increasing production by the foetal adrenal of dehydroepiandrosterone sulphate which, after $16 \alpha$-hydroxylation, may be converted directly to oestriol without oestrone being formed as an intermediate (Kirschner, Wiqvist \& Diczfalusy, 1966). Although the foetal liver, in human mid-pregnancy at least, is the most important site in the foeto-placental unit for the conversion of oestrone and oestradiol to oestriol (Schwers, Eriksson \& Diczfalusy, 1965), there is now a good deal of evidence from studies in animal and human pregnancy to suggest that the activity of the foetal pituitary-adrenal axis influences myometrial contractility. 
The changes we have found in uterine contractility and in the cervix may therefore be initiated from within the foeto-placental unit. Possible mechanisms are discussed later but there is evidence in human pregnancy, for example, that oestrogens have an oxytocic action on the myometrium and can produce changes in the cervix associated with the phenomenon of cervical 'ripening' (Pinto et al., 1964).

\section{Foetal regulation of myometrial contractility Evidence in animals}

Cows. In cattle, Holm (1967) has drawn attention to two syndromes of prolonged pregnancy, attributed to genetic causes. In Guernsey cows, the post-mature foetus shows anterior pituitary aplasia and is immature in size and development. The post-mature Holstein-Friesian calf, although usually large at birth, has hypoplasia of the anterior pituitary. These calves show evidence of adrenal insufficiency (Holm, Parker \& Galligan, 1961) and die in hypoglycaemic coma within hours of delivery unless corticosteroids are administered. In these breeds, pregnancy may be prolonged to over a year and vaginal delivery does not occur until the calf dies in utero.

Goats. In Angora goats, Van Rensburg (1965) showed that the troublesome syndrome of habitual abortion was associated with foetal adrenal hyperplasia and foetal thymic atrophy. These findings are important because they suggest that foetal adrenal function may play an active, rather than a permissive, role in the regulation of myometrial contractility.

Sheep. In the ewe, Binns et al. (1959) reported that in south-western Idaho abnormally long gestation occurred in pregnancies complicated by severe malformation of the foetal head, shown later to be due to maternal ingestion of the plant Veratrum californicum (Binns et al., 1963). In some instances the abnormal foetus grew to excessive size; one lamb which survived in utero for 230 days weighed $26 \mathrm{lb}$ at birth (duration of pregnancy in sheep is 150 days on average). Binns et al. (1959) reported absence of the pituitary in these post-mature lambs but did not comment on the appearance of the adrenals.

The only direct evidence for a foetal role in the onset of labour comes from the work of Liggins and co-workers (Liggins, Holm \& Kennedy, 1966; Liggins, Kennedy \& Holm, 1967) who have shown that in the pregnant ewe, pregnancy can be prolonged by destruction of the foetal lamb pituitary or hypothalamus, or by section of the pituitary stalk. They were able to induce labour by injecting corticotrophin into the hypophysectomized lamb in utero, except in one animal in which the foetal lamb had also been adrenalectomized.

There have been two reports on the effects of bilateral foetal adrenalectomy in pregnant sheep. Van Rensburg (1967) noted that although the foetus continued to grow for a time after the operation, ڤ intra-uterine death usually occurred, followed by abortion. Drost \& Holm (1968) found that preg- $\propto$ nancy lasted 157 days or more in eight of thirty $\rightarrow$ seven ewes in whom this operation had been performed. However, interpretation of their results is 0 complicated by the fact that only one of six 'post-등 mature' single lambs was delivered alive (by Caesa- $\overline{\bar{D}}$. rean section at 159 days gestation), although the $\overparen{\varnothing}$ appearances of the others were said to indicate very recent death and to be in keeping with post-maturity.

\section{Evidence in human pregnancy}

Anencephaly. Evidence that the human foetal $\vec{\rho}$ pituitary-adrenal axis is concerned in the onset of labour has been obtained from studies of anen- 3 . cephaly, a foetal malformation mainly of the central if nervous system, but associated with adrenal hy- $r$ poplasia. Malpas (1933) was among the first to $\overrightarrow{0}$ document the marked tendency to prolonged preg-os nancy in cases of anencephaly uncomplicated by excess amniotic fluid; Comerford (1965) confirmed these observations. We found (Anderson, Laurence $\vec{c}$ $\&$ Turnbull, 1968) that of nine such cases in which the duration of pregnancy was not in doubt, labour began before term in only one case (in the 40th week) and its onset was prolonged up to 46 weeks in the $\overrightarrow{0}$ remainder. We have found, by histological examina tion of the foetal adrenal in these cases, that tise smaller the size of the foetal zone, the more pro longed the pregnancy and the more difficult it was to induce labour. Other workers have demonstrated in anencephaly the almost complete absence of dehydroepiandrosterone sulphate in cord blood $\stackrel{\varrho}{\rightarrow}$ (Easterling et al., 1966) and low levels of maternalö믈 urinary oestriol where the foetal adrenals were hypoplastic (Frandsen \& Stakemann, 1964). In one case where the anencephalic foetus had normal adrenals, excretion of oestriol was normal (Frandsen윽 \& Stakemann, 1964); in the one case in our series in:which labour began in the 40th week, the adrenals 3 were almost normal in size and structure.

\section{Discussion}

Diczfalusy and his colleagues in Stockholm have ${ }^{\circ}$ extensively investigated the metabolism of steroids $\frac{D}{0}$ in the human foeto-placental unit during the first 20 . weeks of pregnancy, a phase during which we have $N$ found the uterus to be quiescent. Little is known N about the changes in steroid biosynthesis and meta-N bolism by the foeto-placental unit during the second ${ }_{\sigma}^{\omega}$ half of pregnancy, but our evidence suggests that the development of increasing uterine contractility and $\stackrel{0}{\leftarrow}$ the onset of labour depends on these changes. It $\stackrel{\Phi}{\leftrightarrow}$ may be that as pregnancy advances, the increasingly active foetal adrenal uses more progesterone, or its precursors, to synthesize corticosteroids and oestro- $\overrightarrow{\mathbb{\Phi}}$ 
gens and thus critically alters the hormonal environment which regulates the activity of the uterus. Alternatively, the vital factor may be increasing oestrogen production by the foetus, for Pinto et al. (1966) have demonstrated increased uterine activity following the intra-amniotic injection of oestradiol$17 \beta$ in human pregnancy and Klopper, Dennis \& Farr (1968) claim a similar effect from oestriol sulphate given by the same route.

Perhaps other steroid hormones such as corticosteroids have greater effects on myometrial contractility than has previously been suspected. Alexander et al. (1968) found a greatly increased foetal sheep adrenal secretion of cortisol, corticosterone and aldosterone towards term. Paterson \& Harrison (1968) suggested that their finding of an increased rate of disappearance of tritium-labelled cortisol from the plasma of pregnant sheep in the last 2 weeks of pregnancy may have been due to foetal secretion of cortisol.

At present the mechanisms involved in initiating labour are little understood. However, we believe that the hypothesis presented, namely, that the onset of labour normally depends on changes in steroid metabolism within the foeto-placental unit brought about by the maturing foetal pituitary-adrenal axis, forms a promising basis for future studies on the regulation of myometrial contractility in pregnancy.

\section{Acknowledgment}

This work was carried out during the tenure of a grant from the Medical Research Council.

\section{References}

Alexander, D.P., Britton, H.G., James, V.H.T., Nixon, D.A., Parker, R.A., Wintour, E.M. \& Wright, R.D. (1968) Steroid secretion by the adrenal gland of foetal and neonatal sheep. J. Endocr. 40, 1.

Anderson, A.B.M. \& Turnbull, A.C. (1968) Spontaneous contractility and oxytocin sensitivity of the human uterus in mid-pregnancy. J. Obstet. Gynaec. Brit. Cmwlth, 75, 271.

ANDERSON, A.B.M., LaurenCe, K.M.\&Turnbull, A.C.(1968) The relationship in anencephaly between the size of the adrenal cortex and the length of gestation. (In preparation.)

Binns, W., Thacker, E.J., James, L.F. \& HufFman W.T. (1959) A congenital cyclopian-type malformation in lambs. J. Amer. vet. med. Ass. 134, 180.

Binns, W., James, L.F., Shupe, J.L. \& Everett, G. (1963) A congenital cyclopian-type malformation in lambs induced by maternal ingestion of a range plant, Veratrum Californicum. Amer. J. vet. Res. 103, 1164.

Cassmer, O. (1959) Hormone production of the isolated human placenta. Acta endocr. (Kbh.), Suppl. 45.

COMERFoRD, J.B. (1965) Pregnancy with anencephaly. Lancet, i, 679.

Diczfalusy, E., Cassmer, O., Alonso, C. \& De Miquel, M. (1961) Oestrogen metabolism in the human foetus and newborn. Recent Progr. Hormone Res. 17, 147.

Drost, M. \& Holm, L.W. (1968) Prolonged gestation in ewes after foetal adrenalectomy. J. Endocr. 40, 293.

Easterling W.E., Jr., Simmer, H.H., Dignam, W.J., Frankland, M.V. \& Naftolin, F. (1966) Neutral $C_{19}$ steroids and steroid sulfates in human pregnancy. II. Dehydroepiandrosterone sulfate, 16a-hydroxydehydro- epiandrosterone, and $16 \alpha$-hydroxydehydroepiandrosterone sulfate in maternal and foetal blood of pregnancies with anencephalic and normal foetuses. Steroids, 8, 157.

Frandsen, V.A. \& Stakemann, G. (1964) The site of production of oestrogenic hormones in human pregnancy. III. Further observations on the hormone excretion in pregnancy with anencephalic foetus. Acta endocr. (Kbh.), 47, 265.

Holm, L.W. (1967) Prolonged pregnancy. Advanc. vet. Sci. 2, 159.

Holm, L.W., Parker, H.R. \& Galligan, S.J. (1961) Adrenal insufficiency in postmature calves. Amer. J. Obstet. Gynec. 81, 1000.

Kirschner, M.A., WiQvist, N. \& Diczfalusy, E. (1966) Studies on oestriol synthesis from dehydroepiandrosterone sulphate in human pregnancy. Acta endocr. (Kbh.), 53, 584.

KlopPer, A. \& Billewicz, W. (1963) Urinary excretion of oestriol and pregnanediol during normal pregnancy. J. Obstet. Gynaec. Brit. Cmivlth, 70, 1024.

Klopper, A.I., DenNis, K.J. \& FARR, V. (1968) Urinary oestriol after intra-amniotic injection of oestriol sulphate. Brit. med. J. ii, 158.

Klopper, A.I., Turnbull, A.C. \& Anderson, A.B.M. (1966) Steroid hormone excretion following intra-amniotic injection of hypertonic saline. J. Obstet. Gynaec. Brit. Cmwlth, 73, 390.

Liggins, G.C., Holm, L.W. \& Kennedy, P.C. (1966) Prolonged pregnancy following surgical lesions of the foetal lamb pituitary. J. Reprod. Fert. 12, 419.

Liggins, G.C., KenNedy, P.C. \& Holm, L.W. (1967) Failure of initiation of parturition after electrocoagulation of the pituitary of the fetal lamb. Amer. J. Obstet. Gynec. 98, 1080.

MalPas, P. (1933) Postmaturity and malformations of the foetus. J. Obstet. Gynaec. Brit. Emp. 40, 1046.

Paterson, J.Y.F. \& Harrison, F.A. (1967) The specific activity of plasma cortisol in sheep during continuous infusion of $\left[1,2-{ }^{3} \mathrm{H}_{2}\right]$ cortisol, and its relation to the rate of cortisol secretion. J. Endocr. 40, 37.

Pinto, R.M., Fisch, L., Schwarcz, R.L. \& Montuori, E. (1964) Action of oestradiol-17ß upon uterine contractility and the milk-ejecting effect in the pregnant woman. Amer. J. Obstet. Gynec. 90, 99.

Pinto, R.M., Lerner, U., Mazzocco, N. \& Glauberman, M. (1966) The oxytocic action of intra-amniotic oestradiol$17 \beta$ on the pregnant human uterus. Amer. J. Obstet. Gynec. 94, 876.

Schwers, J., Eriksson, G. \& Diczfalusy, E. (1965) Metabolism of oestrone and oestradiol in the human foetoplacental unit at midpregnancy. Acta endocr. (Kbh.), 49, 65.

Turnbull, A.C. \& ANDERSON, A.B.M. (1967) Induction of labour. I. Amniotomy. J. Obstet. Gynaec. Brit. Cmwlth, 74, 849.

Turnbull, A.C. \& Anderson, A.B.M. (1968a) Induction of labour. II. Intravenous oxytocin infusion. J. Obstet. Gynaec. Brit. Cmwlth, 75, 24.

Turnbull, A.C. \& ANDERSON, A.B.M. (1968b) Induction of labour. III. Results with amniotomy and oxytocin 'titration'. J. Obstet. Gynaec. Brit. Cmwlth, 75, 32.

Turnbull, A.C. \& Anderson, A.B.M. (1968c) Uterine contractility and oxytocin sensitivity during human pregnancy in relation to the onset of labour. J. Obstet. Gynaec. Brit. Cmwlth, 75, 278.

Turnbull, A.C., Anderson, A.B.M. \& Wilson, G.R. (1967) Maternal urinary oestrogen excretion as evidence of a foetal role in determining gestation at labour. Lancet, ii, 627 .

VAN Rensburg, S.J. (1965) Adrenal function and fertility. J.S.Afr. vet.med.Ass. 36, 491.

VAN RENSBURG, S.J. (1967) Gestation in sheep after foetal adrenalectomy and cortisol acetate administration. J.Endocr. 38, 83. 